\title{
A transient CRISPR/Cas9 expression system for genome editing in Trypanosoma brucei
}

\author{
Sebastian Shaw ${ }^{1,2,3}$, Sebastian Knüsel ${ }^{1}$, Sarah Hoenner ${ }^{1}$ and Isabel Roditi ${ }^{*}$ (D)
}

\begin{abstract}
Objective: Generation of knockouts and in situ tagging of genes in Trypanosoma brucei has been greatly facilitated by using CRISPR/Cas9 as a genome editing tool. To date, this has entailed using a limited number of cell lines that are stably transformed to express Cas9 and T7 RNA polymerase (T7RNAP). It would be desirable, however, to be able to use CRISPR/Cas9 for any trypanosome cell line.

Results: We describe a sequential transfection expression system that enables transient expression of the two proteins, followed by delivery of PCR products for gRNAs and repair templates. This procedure can be used for genome editing without the need for stable integration of the Cas9 and T7RNAP genes.
\end{abstract}

Keywords: CRISPR/Cas9, Transient transfection, Trypanosome

\section{Introduction}

The establishment of genome editing by CRISPR/Cas9 in trypanosomatids has greatly increased the ease with which knockouts can be generated, as two copies of a non-essential gene can often be deleted in a single round of transfection. The system most widely used for Trypanosoma brucei entails creating cell lines which express (either constitutively or inducibly) both Cas9 to generate a DNA double-strand break and T7RNAP for the transcription of guide RNAs from a DNA template [1-4]. The original pTB011 plasmid generated for T. brucei [4] encodes Cas 9 flanked by tubulin sequences, enabling the construct to be integrated into the corresponding multicopy array. We modified this plasmid by replacing the puromycin acetyltransferase gene with that of T7RNAP, giving rise to pTB011_Cas9_T7RNAP_blast (Fig. 1a). This plasmid allows generation of CRISPR/Cas9-competent cell lines, constitutively expressing T7RNAP and Cas9 from the tubulin locus, in a single round of transfection [5]. Further modification of this plasmid, and

*Correspondence: isabel.roditi@izb.unibe.ch

${ }^{1}$ Institute of Cell Biology, University of Bern, Bern, Switzerland

Full list of author information is available at the end of the article optimisation of the transfection protocol for transient expression of the proteins and guide RNAs, are described below.

\section{Main text}

Results

In order to expand the range of cell lines that can be genetically modified by CRISPR/Cas9, without the need for stable transformation, we developed a protocol for transient expression of all three components (Cas9, T7RNAP and guide RNAs) in T. brucei. The plasmid Allin-one-Cas9 (pAi1C9; Fig. 1b) was constructed by replacing the $\alpha$-tubulin sequence upstream of T7RNAP with $366 \mathrm{bp}$ of the EP procyclin promoter and $5^{\prime}$ UTR [6].

To test the functionality of the plasmid, we used the LeishGEdit software [4] to design a guide RNA that allows tagging of the $\mathrm{C}$-terminus of phosphodiesterase B1 (PDEB1) with mNeonGreen (mNG). The repair template, in the form of a purified PCR product, including homology arms of $30 \mathrm{bp}$ on each side, was amplified from pPOTv7 [7]. As a positive control we transfected a derivative of T. brucei Lister 427 procyclic forms that already

(c) The Author(s) 2020. This article is licensed under a Creative Commons Attribution 4.0 International License, which permits use, sharing, adaptation, distribution and reproduction in any medium or format, as long as you give appropriate credit to the original author(s) and the source, provide a link to the Creative Commons licence, and indicate if changes were made. The images or other third party material in this article are included in the article's Creative Commons licence, unless indicated otherwise in a credit line to the material. If material is not included in the article's Creative Commons licence and your intended use is not permitted by statutory regulation or exceeds the permitted use, you will need to obtain permission directly from the copyright holder. To view a copy of this licence, visit http://creativecommons.org/licenses/by/4.0/. The Creative Commons Public Domain Dedication waiver (http://creativecommons.org/publicdomain/zero/1.0/) applies to the data made available in this article, unless otherwise stated in a credit line to the data. 

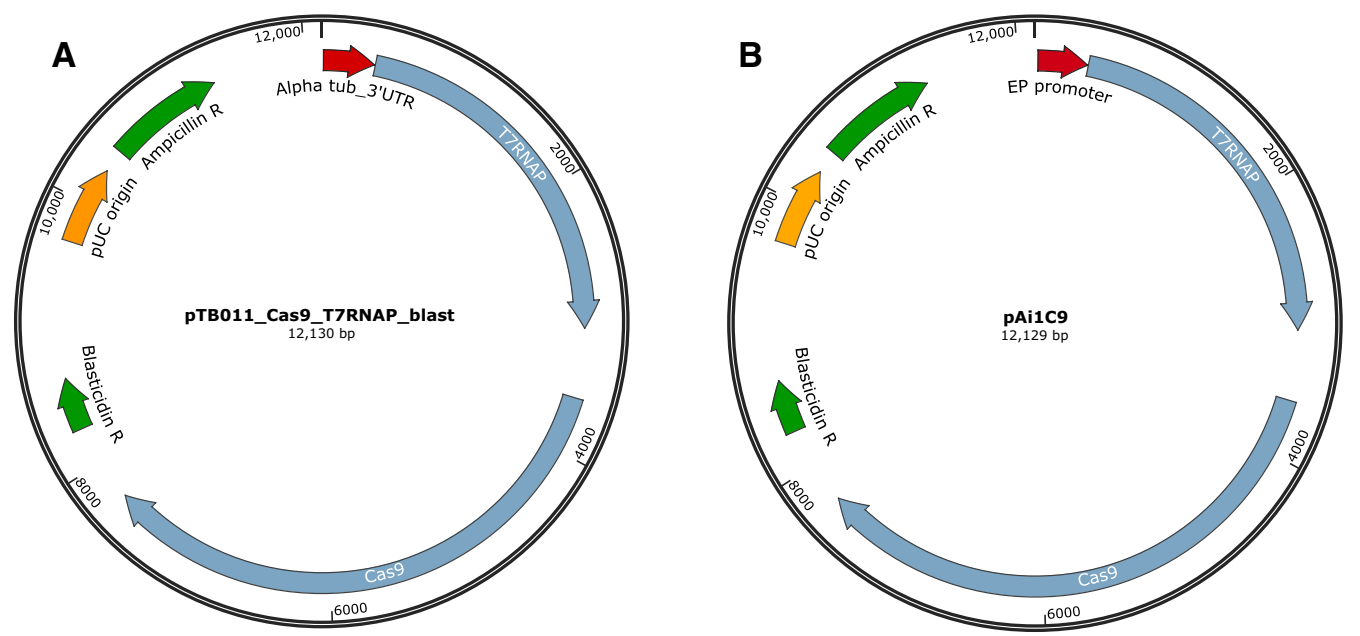

Fig. 1 Plasmid maps of a pTB011_Cas9_T7RNAP_blast and b pAi1C9

expresses Cas9 and T7RNAP constitutively (Lister 427/ Cas9) [5]. This gave rise to cells with a fluorescent flagellum as expected (tryptag.org) (Fig. 2a).

For genome editing by transient expression of Cas9 and T7RNAP, we tested two different transfection schemes. Initially, all components were transfected simultaneously: the circular plasmid pAi1C9 encoding Cas9 and T7RNAP, the DNA template for in vivo transcription of a guide RNA, and the DNA repair template harbouring $\mathrm{mNG}$ for $\mathrm{C}$-terminal tagging and a hygromycin resistance gene. This procedure gave few hygromycinresistant clones, only 10 clones in total, from 4 separate transfections. These clones either did not express mNG (4 clones), or expressed it as a cytoplasmic protein (2 clones) or expressed it correctly localised to the flagellum (4 clones). Examples are shown in Fig. 2b. We hypothesise that, due to insufficient expression of Cas9 and T7RNAP, the amounts of site-specific guide RNAs and double-strand breaks at the correct locus were too low to drive efficient integration by homology-directed repair.

We therefore tested sequential transfections in which we first used pAi1C9 to enable expression of Cas9 and T7RNAP. A second transfection $20 \mathrm{~h}$ later provided the templates for the gRNA and the mNG repair construct. The same electroporation conditions were used for the plasmid and the templates (see Methods and Fig. 3). This procedure yielded 20 clones. There were 16 clones in which $\mathrm{mNG}$ was correctly localised to the flagellum, one in which it was cytoplasmic, 2 clones with mixed populations of $\mathrm{mNG}$ localised either to the flagellum or the cytoplasm, and one that was negative (see Fig. 2b for representative examples). One clone with flagellar mNeonGreen had a fluorescence intensity twice that of the others (clone B1) and might have been tagged on both alleles.

We have also used this procedure of sequential transfections to simultaneously knock out both copies of trypanin or GPI-anchor transamidase subunit 8 (GPI8), which are non-essential genes in cultured procyclic form T. brucei $[8,9]$. Genotyping data is provided in Additional file 1.

\section{Methods}

\section{Transfection of pAi1C9}

$4 \times 10^{7}$ T. b. brucei 427 procyclic forms were transfected with $10 \mu \mathrm{g}$ pAilC9 dissolved in $100 \mu \mathrm{l}$ TbBSF transfection buffer [10], using an Amaxa Nucleofector IIb (Lonza), program X-014 [11]. Cells were transferred to $13 \mathrm{ml}$ SDM79 medium [12] supplemented with $10 \%$ FBS and incubated at $27^{\circ} \mathrm{C}$ and $2.5 \% \mathrm{CO}_{2}$ for $20 \mathrm{~h}$.

\section{Transfection of pooled PCR products for repair constructs and sgRNA templates}

The entire culture from the first transfection was centrifuged at $1700 \mathrm{~g}$ for $5 \mathrm{~min}$, the supernatant discarded and the cells resuspended in $100 \mu \mathrm{l}$ TbBSF transfection buffer containing the pooled PCR products (see protocol for PCRs below). For tagging one sgRNA template (targeted to the $3^{\prime}$ end of the ORF) and one repair template (hygromycin resistance) were provided; to generate the knockouts, we provided two sgRNA templates (targeted to the $5^{\prime}$ and $3^{\prime}$ ends of the ORF) and two repair templates (hygromycin and neomycin resistance genes).

Transfection was performed as described above and the cells were transferred to $10 \mathrm{ml}$ SDM79 supplemented with $10 \%$ FBS. The cells were diluted 1:5, 1:50 
A

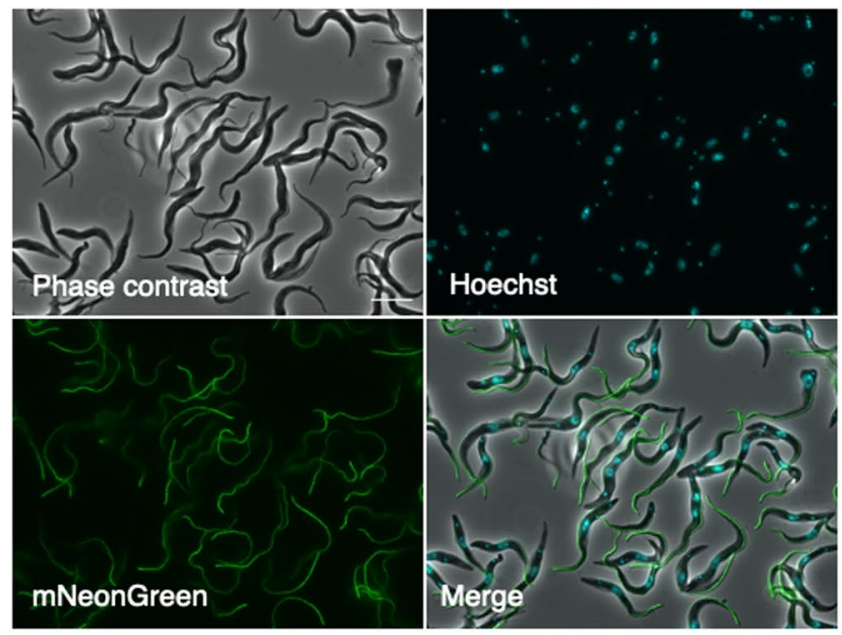

B
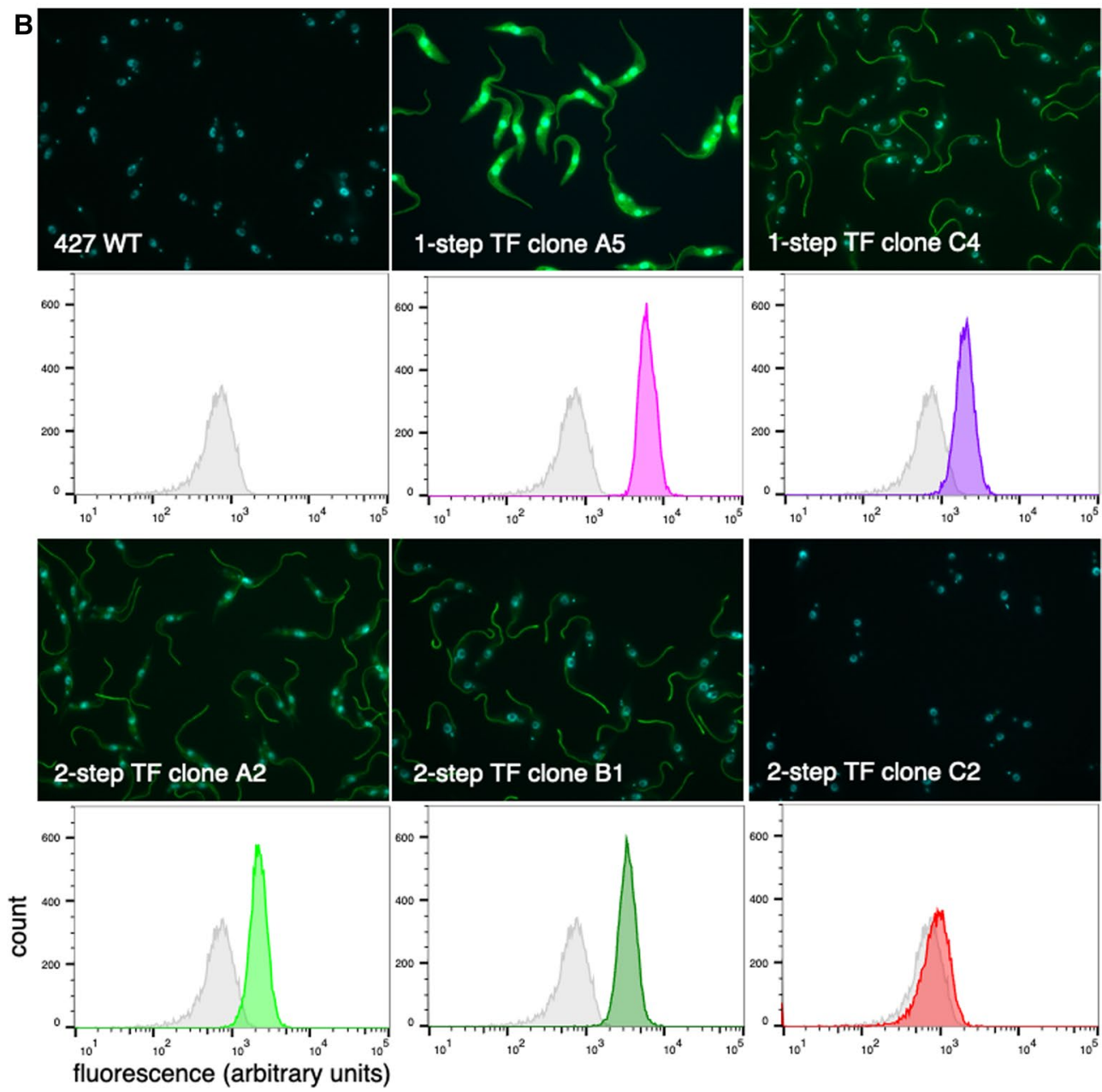

Fig. 2 Trypanosomes tagged with mNeonGreen at the C-terminus of phosphodiesterase B1 (PDEB1). a Tagging PDEB1 in Lister 427/Cas9. Scale bar: 10 microns. b Tagging PDEB1 in Lister 427. Fluorescence intensity of live cells was quantified with a benchtop flow cytometer (ACEA NovoCyte). To remove particles of subcellular size, a cut-off of $3 \times 10^{4}$ was applied to the forward scatter. A total of $10^{4}$ events were recorded and analysed using FlowJo software without gating. TF transfection 


\section{A In situ tagging}

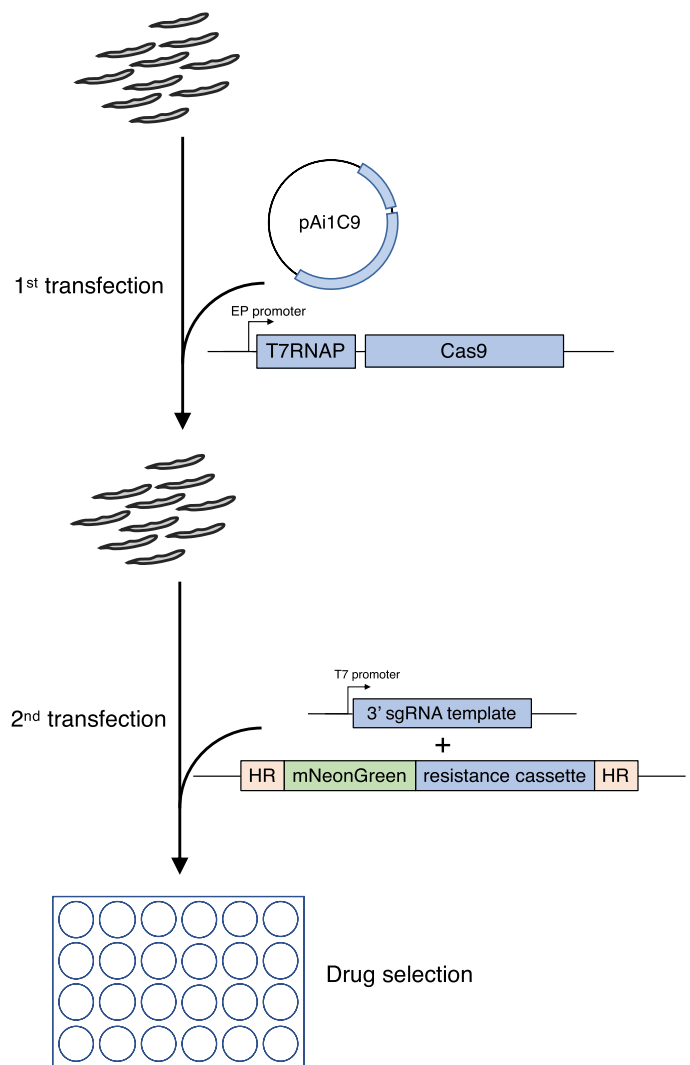

B Knockout

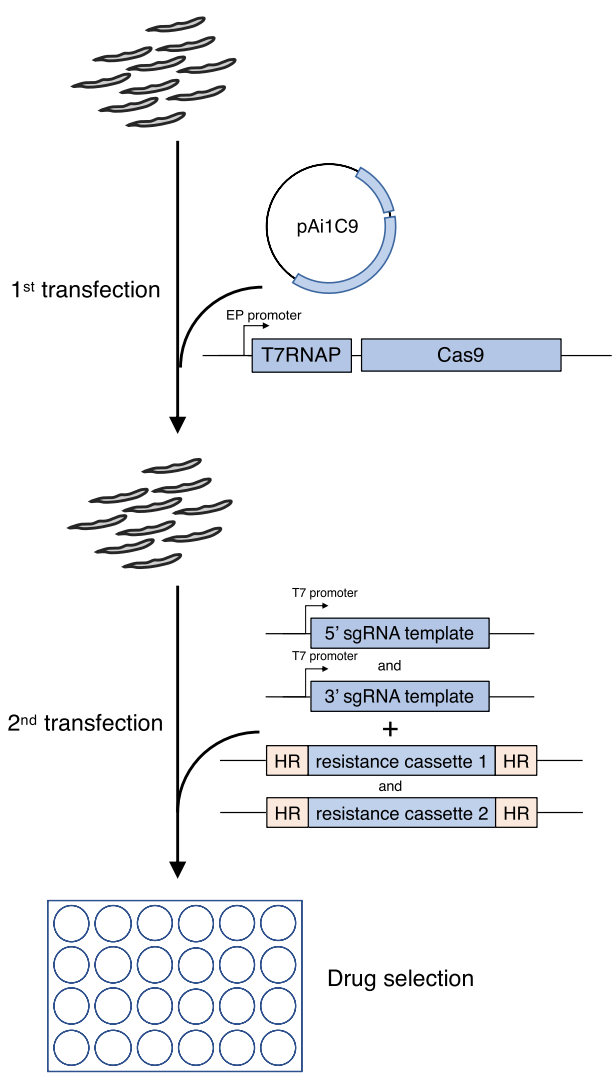

Fig. 3 Flow chart of sequential transfections. Procyclic form trypanosomes were transfected first with pAi1 C9 to allow expression of Cas9 and T7RNAP. After $20 \mathrm{~h}$, the pool of trypanosomes was transfected a second time to provide the templates for gRNA(s) and the repair template(s)/ resistance cassette(s)

and 1:500 in conditioned medium (fresh medium $+20 \%$ supernatant of a log-phase culture) and distributed into 24-well plates ( $1 \mathrm{ml}$ in each well). Transformants were selected using $25 \mu \mathrm{g} \mathrm{m}{ }^{-1}$ Hygromycin B and/ or $15 \mu \mathrm{g} \mathrm{ml} \mathrm{m}^{-1}$ Geneticin; stable clones were obtained 2 weeks post selection.

\section{Polymerase chain reactions (PCR)}

Reactions were performed with reagents from New England Biolabs: Phusion High-Fidelity DNA polymerase (M0530S), 5x Phusion HF buffer (B0519S) and dNTP mix (N0447S). Cycling conditions are identical to those previously published $[4,13]$.

- 1st PCR: template for sgRNAs; two $20 \mu$ reactions per target.
$4 \mu \mathrm{l} 5 \mathrm{x}$ Phusion HF buffer

$0.5 \mu \mathrm{ldNTP} \operatorname{mix}(250 \mu \mathrm{M})$

$1 \mu \mathrm{l}$ sgRNA primer $(0.5 \mu \mathrm{M})$

$0.2 \mu \mathrm{l}$ Phusion High-Fidelity DNA polymerase $(0.4 \mathrm{U})$

$13.3 \mu \mathrm{l} \mathrm{H}_{2} \mathrm{O}$

- Program:

1) $30^{\prime \prime}, 98^{\circ} \mathrm{C}$

2) $10^{\prime \prime}, 98^{\circ} \mathrm{C}$

3) $30^{\prime \prime}, 60^{\circ} \mathrm{C}$

4) $15^{\prime \prime}, 72^{\circ} \mathrm{C}$

5) go to step 2,35 cycles in total

6) $10^{\prime}, 72^{\circ} \mathrm{C}$

7) hold at $10^{\circ} \mathrm{C}$

$1 \mu \mathrm{l} \mathrm{G00} \mathrm{primer}(0.5 \mu \mathrm{M})$ 
- 2nd PCR: template for resistance gene; two $40 \mu \mathrm{l}$ reactions per resistance gene

$2 \mu \mathrm{l} 60$ ng pPOTv7 mNG (hygro or G418) plasmid

$8 \mu \mathrm{l} 5 \mathrm{x}$ Phusion HF buffer

$1 \mu \mathrm{l}$ dNTP mix $(250 \mu \mathrm{M})$

$2 \mu \mathrm{l}$ Upstream forward primer $(0.5 \mu \mathrm{M})$

$2 \mu \mathrm{l}$ Downstream reverse KO/TAG primer $(0.5 \mu \mathrm{M})$

$0.4 \mu \mathrm{l}$ Phusion High-Fidelity DNA polymerase (0.4U)

$24.6 \mu \mathrm{H} \mathrm{H}_{2} \mathrm{O}$

- Program:
1) $5^{\prime}, 94^{\circ} \mathrm{C}$
2) $30^{\prime \prime}, 94^{\circ} \mathrm{C}$
3) $30^{\prime \prime}, 65^{\circ} \mathrm{C}$
4) $2^{\prime} 30^{\prime \prime}, 72^{\circ} \mathrm{C}$
5) go to step 2,40 cycles in total
6) $10^{\prime}, 72{ }^{\circ} \mathrm{C}$
7) hold at $10{ }^{\circ} \mathrm{C}$

\section{DNA purification after PCR}

PCR reactions were pooled and extracted with 1 volume water-saturated phenol $(\mathrm{pH} 8)$, followed by extraction with 1 volume chloroform. DNA was precipitated from the aqueous phase by addition of 0.1 volume $3 \mathrm{M}$ sodium acetate, $\mathrm{pH} 5.2$, and 3 volumes ice-cold ethanol. The DNA was pelleted by centrifugation, washed twice with $1 \mathrm{ml} \mathrm{80 \%} \mathrm{ethanol,} \mathrm{air-dried} \mathrm{at} \mathrm{room} \mathrm{temperature,} \mathrm{dis-}$ solved in $40 \mu \mathrm{l}$ Milli-Q-water and stored at $-20{ }^{\circ} \mathrm{C}$ until transfection.

\section{Primers}

G00: aaaagcaccgactcggtgccacttttcaagttgataacggactagccttattttaacttgctatttctagctctaaaac

PDEB1 3' sgRNA primer:

gaaattaatacgactcactataggTGAAGAAGTCAGTTGACC

GGgttttagagctagaaatagc

Trypanin $5^{\prime}$ sgRNA primer:

gaattaatacgactcactataggCAAAAACGAGAAGAG

CCTACgttttagagctagaaatagc

Trypanin 3 ' sgRNA primer:

gaaattaatacgactcactataggAGGTGTTGTGGTTCACAC

GTgttttagagctagaaatagc

GPI8 5' sgRNA primer:

gaaattaatacgactcactataggCGGTTGCAAAAAACGAAT

GCgttttagagctagaaatagc

GPI8 3 ' sgRNA primer:

gaaattaatacgactcactataggGGTATGTCCCATCAGTTG

GAgttttagagctagaaatagc

Trypanin upstream forward primer:
TAC TTT TCAGAC TGCATCGTGGCG TACCCC gtataatgcagacctgctgC

Trypanin downstream reverse $\mathrm{KO}$ primer:

CTGCAACAAAGCCGTAACTTGGAACAACCA

ccggaaccactaccagaacc

PDEB1 downstream forward primer:

ACGAGT TCTGGCAACAACAGCAGTACTCGT

ggttctggtagtggttccgg

PDEB1 downstream reverse TAG:

ATC ACC ATT GACAAGAACGTACATCTACCA ccaatttgagagacctgtgc

GPI8 upstream forward primer:

T TGGATCAGGCGCTTGCATAT TTAT T TCCA gtataatgcagacctgctgC

GPI8 downstream reverse $\mathrm{KO}$ primer:

AGT TTCAGGAAGGAAGTTCGT TTT TCTCCT

ccggaaccactaccagaacc

\section{Limitations}

Transient transfection with pAi1C9 gives rise to fewer clones than cell lines that are stably transformed with the T7RNAP and Cas9 genes. It has the advantage, however, that it can be applied to any T. brucei cell line. Moreover, in contrast to stable integration of the CRISPR/Cas9 machinery, transient transfection does not require additional selectable markers and it has the added advantage that it circumvents possible Cas9 toxicity. In addition to using Cas9 for deletion, mutation, tagging or integration of ectopic copies, this procedure could also be adapted for nuclease inactive Cas9 variants for targeting RNAs or epigenetic modifications $[14,15]$.

\section{Supplementary information}

Supplementary information accompanies this paper at https://doi. org/10.1186/s13104-020-05089-z.

Additional file 1: Validation of knockout (KO) clones. A+B Trypanin-KO (Tb427.10.6350). A Clonal selection of stable transformants in 24-well plates. Dilutions from transfected pool cultures and number of cells seeded are indicated. Circles depict wells containing cells with successful (O) or unsuccessful (O) genome editing. B Assessment of editing by genotyping PCR and agarose gel electrophoresis. Genes amplified from genomic DNA and target loci are indicated. Lanes corresponding to validated $\mathrm{KO}$ clones are marked with green circles. C+D GPI8-KO (Tb427.10.13860) in a cell line allowing inducible expression of an ectopic copy of GPI8. C as in A. D as in B. E List of primers used for genotyping PCRs of Trypanin-KO (left panels) and GPI8-KO (right panels).

\section{Abbreviations}

mNG: mNeonGreen; PDEB1: Phosphodiesterase B1;T7RNAP: T7 RNA polymerase.

\section{Acknowledgements}

We thank Eva Gluenz (University of Glasgow) for providing the progenitor plasmid pTB011 and David Schädeli and Peter Bütikofer for initiating us into CRISPR/Cas9 technology. 


\section{Authors' contributions}

Designed study: SS and IR; performed experiments: SS, SH and SK; analysed data: SS, SK and IR; wrote the paper: SS, SK and IR. All authors read and approved the final manuscript.

\section{Funding}

Swiss National Science Foundation (Grant nos. 31003A_166427 and 310030_184669) and the Canton of Bern.

\section{Availability of data and materials}

Plasmids are available on request from Isabel Roditi (Isabel.roditi@izb.unibe. ch). The nucleotide sequences of pTB011_Cas9_T7RNAP_blast and pAi1C9 are provided on this website: https://www.izb.unibe.ch/research/prof_dr_isabe I_roditi/index_eng.html.

\section{Ethics approval and consent to participate}

Not applicable.

\section{Consent for publication}

Not applicable.

\section{Competing interests}

We, the authors, declare no conflict of interests.

\section{Author details}

${ }^{1}$ Institute of Cell Biology, University of Bern, Bern, Switzerland. ${ }^{2}$ Graduate School of Cellular and Biomedical Science, University of Bern, Bern, Switzerland. ${ }^{3}$ Present Address: Department of Pathobiology, School of Veterinary Medicine, University of Pennsylvania, 380 South University Avenue, Philadelphia, PA 19104, USA. Received: 4 April 2020 Accepted: 13 May 2020

\section{References}

1. Vasquez J-J, Wedel C, Cosentino RO, Siegel TN. Exploiting CRISPR-Cas9 technology to investigate individual histone modifications. Nucleic Acids Res. 2018;46:e106. https://doi.org/10.1093/nar/gky517.

2. Soares Medeiros LC, South L, Peng D, Bustamante JM, Wang W, Bunkofske M, et al. Rapid, selection-free, high-efficiency genome editing in protozoan parasites using CRISPR-Cas9 ribonucleoproteins. MBio. 2017;8:e01788. https://doi.org/10.1128/mBio.01788-17.

3. Rico E, Jeacock L, Kováŕová J, Horn D. Inducible high-efficiency CRISPRCas9-targeted gene editing and precision base editing in African trypanosomes. Sci Rep. 2018;8:7960. https://doi.org/10.1038/s41598-01826303-w.
4. Beneke T, Madden R, Makin L, Valli J, Sunter J, Gluenz E. A CRISPR Cas9 high-throughput genome editing toolkit for kinetoplastids. R Soc open Sci. 2017:4:170095. https://doi.org/10.1098/rsos.170095.

5. Shaw S, DeMarco SF, Rehmann R, Wenzler T, Florini F, Roditi I, Hill KL. Flagellar CAMP signaling controls trypanosome progression through host tissues. Nat Commun. 2019;10:1-3.

6. Furger A, Schürch $N$, Kurath $U$, Roditi I. Elements in the $3^{\prime}$ untranslated region of procyclin $\mathrm{mRNA}$ regulate expression in insect forms of Trypanosoma brucei by modulating RNA stability and translation. Mol Cell Biol. 1997;17:4372-80. https://doi.org/10.1128/mcb.17.8.4372.

7. Dean S, Sunter J, Wheeler RJ, Hodkinson I, Gluenz E, Gull K. A toolkit enabling efficient, scalable and reproducible gene tagging in trypanosomatids. Open Biol. 2015;5:140197. https://doi.org/10.1098/rsob.140197.

8. Hutchings NR, Donelson JE, Hill KL. Trypanin is a cytoskeletal linker protein and is required for cell motility in African trypanosomes. J Cell Biol. 2002;156:867-77. https://doi.org/10.1083/jcb.200201036.

9. Lillico S, Field MC, Blundell P, Coombs GH, Mottram JC. Essential roles for GPI-anchored proteins in African trypanosomes revealed using mutants deficient in GPI8. Mol Biol Cell. 2003;14:1182-94. https://doi.org/10.1091/ mbc.e02-03-0167.

10. Schumann Burkard G, Jutzi P, Roditi I. Genome-wide RNAi screens in bloodstream form trypanosomes identify drug transporters. Mol Biochem Parasitol. 2011;175:91-4. https://doi.org/10.1016/j.molbiopara 2010.09.002

11. Burkard G, Fragoso CM, Roditi I. Highly efficient stable transformation of bloodstream forms of Trypanosoma brucei. Mol Biochem Parasitol. 2007;153:220-3. https://doi.org/10.1016/j.molbiopara.2007.02.008.

12. Brun $R$, Schönenberger M. Cultivation and in vitro cloning of procyclic culture forms of Trypanosoma brucei in a semi-defined medium. Short communication. Acta Trop. 1979;36:289-92.

13. Schädeli D, Serricchio M, Ben Hamidane H, Loffreda A, Hemphill A, Beneke T, et al. Cardiolipin depletion-induced changes in the Trypanosoma brucei proteome. FASEB J. 2019;33:13161-75.

14. Adli M. The CRISPR tool kit for genome editing and beyond. Nat Commun. 2018;9:1911. https://doi.org/10.1038/s41467-018-04252-2.

15. Pickar-Oliver A, Gersbach CA. The next generation of CRISPR-Cas technologies and applications. Nat Rev Mol Cell Biol. 2019;20:490-507. https ://doi.org/10.1038/s41580-019-0131-5.

\section{Publisher's Note}

Springer Nature remains neutral with regard to jurisdictional claims in published maps and institutional affiliations.
Ready to submit your research? Choose BMC and benefit from:

- fast, convenient online submission

- thorough peer review by experienced researchers in your field

- rapid publication on acceptance

- support for research data, including large and complex data types

- gold Open Access which fosters wider collaboration and increased citations

- maximum visibility for your research: over $100 \mathrm{M}$ website views per year

At BMC, research is always in progress.

Learn more biomedcentral.com/submissions 